Annals of Pure and Applied Mathematics

Vol. 16, No. 1, 2018, 47-51

ISSN: 2279-087X (P), 2279-0888(online)

Published on 1 January 2018

Annals of

www.researchmathsci.org

DOI: http://dx.doi.org/10.22457/apam.v16n1a6

Pure and Applied

Mathematics

\title{
Reverse Zagreb and Reverse Hyper-Zagreb Indices and their Polynomials of Rhombus Silicate Networks
}

\author{
V.R.Kulli
}

Department of Mathematics

Gulbarga University, Gulbarga 585106, India

e-mail: vrkulli@gmail.com

Received 11 December 2017; accepted 14 December 2017

Abstract. We propose the first and second reverse hyper-Zagreb indices of a graph. In this paper, we compute the first two reverse Zagreb indices, the first two reverse hyperZagreb indices and their polynomials of rhombus silicate networks.

Keywords: reverse Zagreb index, reverse hyper-Zagreb index, rhombus silicate network

AMS Mathematics Subject Classification (2010): 05C05, 05C12, 05 C 35

\section{Introduction}

Let $G=(V(G), E(G))$ be a finite, undirected without loops and multiplied edges. The degree $d_{G}(v)$ is the number of vertices adjacent to $v$. Let $\Delta(G)$ denote the maximum degree among the vertices of $G$. The reverse vertex degree of a vertex $v$ in $G$ is defined as $c_{v}=\Delta(G)-d_{G}(v)+1$. The reverse edge connecting the reverse vertices $u$ and $v$ will be denoted by $u v$. We refer [1] for undefined term and notation.

A molecular graph is a graph whose vertices correspond to the atoms and the edges to the bonds. Chemical graph theory has an important effect on the development of the Chemical Sciences. A single number that can be used to characterize some property of the graph of molecular is called a topological index. Numerous topological indices have been considered in Theoretical Chemistry see [2].

The first reverse Zagreb beta index and second reverse Zagreb index [3] of a graph $G$ are respectively defined as

$$
C M_{1}(G)=\sum_{u v \in E(G)}\left(c_{u}+c_{v}\right), \quad C M_{2}(G)=\sum_{u v E E(G)} c_{u} c_{v} .
$$

These indices were also studied, for example, in $[4,5]$.

We now introduce the first and second reverse hyper-Zagreb indices of a graph $G$

as

$$
H C M_{1}(G)=\sum_{u v E(G)}\left(c_{u}+c_{v}\right)^{2}, \quad H C M_{2}(G)=\sum_{u v E(G)}\left(c_{u} c_{v}\right)^{2} .
$$

Considering the first and second reverse Zagreb indices, we introduce the first and second reverse Zagreb polynomials as 
V.R.Kulli

$C M_{1}(G, x)=\sum_{u v \in E(G)} x^{c_{u}+c_{v}}, \quad C M_{2}(G, x)=\sum_{u v \in E(G)} x^{c_{u} c_{v}}$.

Also considering the first and second reverse hyper-Zagreb indices, we introduce the first and second reverse hyper-Zagreb polynomials as

$$
H C M_{1}(G, x)=\sum_{u v E(G)} x^{\left(c_{u}+c_{v}\right)^{2}}, \quad H C M_{2}(G, x)=\sum_{u v \in E(G)} x^{\left(c_{u} c_{v}\right)^{2}},
$$

Recently many topological indices were studied, for example, in $[6,7,8,9,10$, $11,12,13,14,15,16]$.

In this paper, we determine the first two reverse Zagreb indices, the first two reverse hyper-Zagreb indices, and their polynomials of rhombus silicate networks. For networks see [17] and references cited therein.

\section{Results for Rhombus Silicate networks}

Silicates are obtained by fusing metal oxides or metal carbonates with sand. In this section, we consider a family of rhombus silicate networks. This network is symbolized by $R H S L_{n}$. A 3-dimensional rhombus silicate network is depicted in Figure 1.

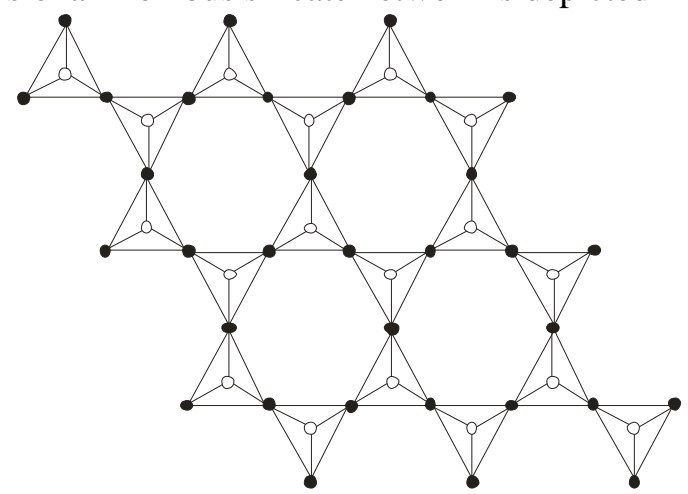

Figure 1: A 3-dimensional rhombus silicate network

Theorem 1. The first and second reverse Zagreb indices of rhombus silicate network $R H S L_{n}$ are

(i) $C M_{1}\left(R H S L_{n}\right)=42 n^{2}+36 n$. (ii) $C M_{2}\left(R H S L_{n}\right)=30 n^{2}+72 n+18$.

Proof: Let $G$ be the graph of rhombus silicate network $R H S L_{n}$. The graph $G$ has $5 n^{2}+2 n$ vertices and $12 n^{2}$ edges. From Figure 1, we see that the vertices of $R H S L_{n}$ are either of degree 3 or 6 . Thus $\Delta(G)=6$. In $R H S L_{n}$, by algebraic method, there are three types of edges as follows:

$$
\begin{array}{ll}
E_{33}=\left\{u v \in E(G) \mid d_{G}(u)=d_{G}(v)=3\right\}, & \left|E_{33}\right|=4 n+2 . \\
E_{36}=\left\{u v \in E(G)\left|d_{G}(u)\right|=3, d_{G}(v)=6\right\}, & \left|E_{36}\right|=6 n^{2}+4 n-4 . \\
E_{66}=\left\{u v \in E(G)\left|d_{G}(u)\right|=d_{G}(v)=6\right\}, & \left|E_{66}\right|=6 n^{2}-8 n+2 . \\
\text { Clearly we have } c_{u}=\Delta(G)-d_{G}(u)+1=7-d_{G}(u) . & \\
\text { We now see that there are three types of reverse edges as follows: } & \\
C E_{44}=\left\{u v \in E(G) \mid c_{u}=c_{v}=4\right\}, & \left|C E_{44}\right|=4 n+2 . \\
C E_{41}=\left\{u v \in E(G) \mid c_{u}=4, c_{v}=1\right\}, & \left|C E_{41}\right|=6 n^{2}+4 n-4 . \\
C E_{11}=\left\{u v \in E(G) \mid c_{u}=c_{v}=1\right\}, & \left|C E_{11}\right|=6 n^{2}-8 n+2 .
\end{array}
$$


Reverse Zagreb and Reverse Hyper-Zagreb Indices and their Polynomials of Rhombus Silicate Networks

(i) To compute $C M_{1}\left(R H S L_{n}\right)$, we see that

$$
\begin{aligned}
C M_{1}\left(R H S L_{n}\right) & =\sum_{u v E(G)}\left(c_{u}+c_{v}\right)=\sum_{E E_{44}}\left(c_{u}+c_{v}\right)+\sum_{R E_{41}}\left(c_{u}+c_{v}\right)+\sum_{R E_{11}}\left(c_{u}+c_{v}\right) \\
& =(4+4)(4 n+2)+(4+1)\left(6 n^{2}+4 n-4\right)+(1+1)\left(6 n^{2}-8 n+2\right) \\
& =42 n^{2}+36 n .
\end{aligned}
$$

(ii) To compute $\mathrm{CM}_{2}\left(R H S L_{n}\right)$, we see that

$$
\begin{aligned}
C M_{2}\left(R H S L_{n}\right) & =\sum_{u v \in E(G)} c_{u} c_{v}=\sum_{E E_{44}} c_{u} c_{v}+\sum_{R E_{41}} c_{u} c_{v}+\sum_{R E_{11}} c_{u} c_{v} \\
& =(4 \times 4)(4 n+2)+(4 \times 1)\left(6 n^{2}+4 n-4\right)+(1 \times 1)\left(6 n^{2}-8 n+2\right) \\
& =30 n^{2}+72 n+18 .
\end{aligned}
$$

Theorem 2. The first and second reverse Zagreb polynomials of rhombus silicate network $R H S L_{n}$ are

(i) $C M_{1}\left(R H S L_{n}, x\right)=(4 n+2) x^{8}+\left(6 n^{2}+4 n-4\right) x^{5}+\left(6 n^{2}-8 n+2\right) x^{2}$.

(ii) $C M_{2}\left(R H S L_{n}, x\right)=(4 n+2) x^{16}+\left(6 n^{2}+4 n-4\right) x^{4}+\left(6 n^{2}-8 n+2\right) x$.

Proof: Let $G=R H S L_{n}$

(i) From equation (3) and by cardinalities of the reverse edge partition of $R H S L_{n}$, we have

$$
\begin{aligned}
C M_{1}\left(R H S L_{n}, x\right) & =\sum_{u v \in E(G)} x^{c_{u}+c_{v}}=\sum_{C E_{44}} x^{c_{u}+c_{v}}+\sum_{C E_{41}} x^{c_{u}+c_{v}}+\sum_{C E_{11}} x^{c_{u}+c_{v}} \\
& =(4 n+2) x^{4+4}+\left(6 n^{2}+4 n-4\right) x^{4+1}+\left(6 n^{2}-8 n+2\right) x^{1+1} \\
& =(4 n+2) x^{8}+\left(6 n^{2}+4 n-4\right) x^{5}+\left(6 n^{2}-8 n+2\right) x^{2} .
\end{aligned}
$$

(ii) From equation (3), and by cardinalities of the reverse edge partition of $R H S L_{n}$, we have

$$
\begin{aligned}
C M_{2}\left(R H S L_{n}, x\right) & =\sum_{u v E(G)} x^{c_{u} c_{v}}=\sum_{C E_{44}} x^{c_{u} c_{v}}+\sum_{C E_{41}} x^{c_{u} c_{v}}+\sum_{C E_{11}} x^{c_{u} c_{v}} \\
& =(4 n+2) x^{4 \times 4}+\left(6 n^{2}+4 n-4\right) x^{4 \times 1}+\left(6 n^{2}-8 n+2\right) x^{1 \times 1} \\
& =(4 n+2) x^{16}+\left(6 n^{2}+4 n-4\right) x^{4}+\left(6 n^{2}-8 n+2\right) x .
\end{aligned}
$$

Theorem 3. The first and second reverse hyper-Zagreb indices of rhombus silicate network $R H S L_{n}$ are
(i) $H C M_{1}\left(R H S L_{n}\right)=174 n^{2}+324 n+36$.
(ii) $\mathrm{HCM}_{2}\left(\operatorname{RHSL}_{n}\right)=102 n^{2}+1080 n+450$.

Proof: Let $G=R H S L_{n}$.

(i) From equation (2) and by cardinalities of the reverse edge partition of $R H S L_{n}$, we have

$$
\begin{aligned}
H C M_{1}\left(R H S L_{n}\right) & =\sum_{u v E E(G)}\left(c_{u}+c_{v}\right)^{2}=\sum_{C E_{44}}\left(c_{u}+c_{v}\right)^{2}+\sum_{C E_{41}}\left(c_{u}+c_{v}\right)^{2}+\sum_{C E_{11}}\left(c_{u}+c_{v}\right)^{2} \\
& =(4+4)^{2}(4 n+2)+(4+1)^{2}\left(6 n^{2}+6 n-4\right)+(1+1)^{2}\left(6 n^{2}-8 n+2\right) \\
& =174 n^{2}+324 n+36 .
\end{aligned}
$$


(ii) From equation (2) and by cardinalities of the reverse edge partition of $R H S L_{n}$, we have

$$
\begin{aligned}
H_{C M}\left(R_{2} H S L_{n}\right) & =\sum_{u v E E(G)}\left(c_{u} c_{v}\right)^{2}=\sum_{C E_{44}}\left(c_{u} c_{v}\right)^{2}+\sum_{C E_{41}}\left(c_{u} c_{v}\right)^{2}+\sum_{C E_{11}}\left(c_{u} c_{v}\right)^{2} \\
& =(4 \times 4)^{2}(4 n+2)+(4 \times 1)^{2}\left(6 n^{2}+6 n-4\right)+(1 \times 1)^{2}\left(6 n^{2}-8 n+2\right) \\
& =102 n^{2}+1080 n+450 .
\end{aligned}
$$

Theorem 4. The first and second reverse hyper-Zagreb polynomials of rhombus silicate network $\operatorname{RHSL}_{n}$ are
(i) $H C M_{1}\left(R H S L_{n}, x\right)=(4 n+2) x^{64}+\left(6 n^{2}+4 n-2\right) x^{25}+\left(6 n^{2}-8 n+2\right) x^{4}$.
(ii) $H_{C M}\left(R H S L_{n}, x\right)=(4 n+2) x^{256}+\left(6 n^{2}+4 n-2\right) x^{16}+\left(6 n^{2}-8 n+2\right) x$.

Proof: Let $G=R H S L_{n}$

(i) From equation (4) and by cardinalities of the reverse edge partition of $R H S L_{n}$, we have

$$
\begin{aligned}
H C M_{1}\left(R H S L_{n}, x\right) & =\sum_{u v \in E(G)} x^{\left(c_{u}+c_{v}\right)^{2}}=\sum_{C E_{44}} x^{\left(c_{u}+c_{v}\right)^{2}}+\sum_{C E_{41}} x^{\left(c_{u}+c_{v}\right)^{2}}+\sum_{C E_{11}} x^{\left(c_{u}+c_{v}\right)^{2}} \\
& =(4 n+2) x^{(4+4)^{2}}+\left(6 n^{2}+6 n-4\right) x^{(4+1)^{2}}+\left(6 n^{2}-8 n+2\right) x^{(1+1)^{2}} \\
& =(4 n+2) x^{64}+\left(6 n^{2}+6 n-4\right) x^{25}+\left(6 n^{2}-8 n+2\right) x^{4} .
\end{aligned}
$$

(ii) From equation (4) and by cardinalities of the reverse edge partition of $R H S L_{n}$, we have

$$
\begin{aligned}
H_{C M}\left(R H S L_{n}, x\right) & =\sum_{u v E(G)} x^{\left(c_{u} c_{v}\right)^{2}}=\sum_{C E_{44}} x^{\left(c_{u} c_{v}\right)^{2}}+\sum_{C E_{41}} x^{\left(c_{u} c_{v}\right)^{2}}+\sum_{C E_{11}} x^{\left(c_{u} c_{v}\right)^{2}} \\
& =(4 n+2) x^{(4 \times 4)^{2}}+\left(6 n^{2}+6 n-4\right) x^{(4 \times 1)^{2}}+\left(6 n^{2}-8 n+2\right) x^{(1 \times 1)^{2}} \\
& =(4 n+2) x^{256}+\left(6 n^{2}+6 n-4\right) x^{16}+\left(6 n^{2}-8 n+2\right) x .
\end{aligned}
$$

\section{REFERENCES}

1. V.R.Kulli, College Graph Theory, Vishwa International Publications, Gulbarga, India (2012).

2. I.Gutman and O.E.Polansky, Mathematical Concepts in Organic Chemistry, Springer, Berlin, (1986).

3. S.Ediz, Maximal graphs of the first reverse Zagreb beta index, TWMS J. App. Eng. Math. accepted for publication.

4. V.R.Kulli, On the sum connectivity reverse index of oxide and honeycomb networks, Journal of Computer and Mathematical Sciences, 8(9) (2017) 408-413.

5. V.R.Kulli, On the product connectivity reverse index of silicate and hexagonal networks, International Journal of Mathematics and its Applications, 5 (4-B) (2017) 175-179.

6. I.Gutman and N.Trinajstić, Graph theory and molecular orbitals. Total $\pi$-electron energy of alternant hydrocarbons, Chem. Phys. Lett. 17, (1972) 535-538. 
Reverse Zagreb and Reverse Hyper-Zagreb Indices and their Polynomials of Rhombus Silicate Networks

7. I.Gutman, V.R.Kulli, B.Chaluvaraju and H.S.Baregowda, On Banhatti and Zagreb indices, Journal of the International Mathematical Virtual Institute, 7(2017) 53-67. DOI : 10.7251/JIMVI1701053G.

8. G.H.Shirdel, H.Rezapour and A.M.Sayadi, The hyper-Zagreb index of graph operations, Iranian J. Math. Chem. 4(2) (2013) 213-220.

9. V.R.Kulli, K-Banhatti indices of graphs, Journal of Computer and Mathematical Sciences, 7(4) (2016) 213-218.

10. V.R.Kulli, On $K$-hyper-Banhatti indices and coindices of graphs, International Research Journal of Pure Algebra, 6(5) (2016) 300-304.

11. V.R.Kulli, The Gourava indices and coindices of graphs, Annals of Pure and Applied Mathematics, 14(1) (2017) 33-38.

DOI:http://dx.doi-org/10.22457/apam.v14n1a4.

12. V.R.Kulli, Computation of some Gourava indices of titania nanotubes, International Journal of Fuzzy Mathematical Archive, 12(2) (2017) 75-81.

DOI : http://dx.doi-org/10.22457/ijfma.v23n2a4.

13. V.R.Kulli, Certain topological indices and their polynomials of dendrimer nanostars, Annals of Pure and Applied Mathematics, 14(2) (2017) 263-268. DOI:http://dx.doi.org/10.22457/apam.v14n2a9.

14. V.R.Kulli, Edge version of F-index, general sum connectivity index of certain nanotubes, Annals of Pure and Applied Mathematics, 14(3) (2017) 449-455. DOI:http://dx.doi.org/10.22457/apam.v14n3a11.

15. V.R.Kulli, Computation of some topological indices of certain networks, International Journal of Mathematical Archive, 8(2) (2017) 99-106.

16. V.R.Kulli, The product connectivity Gourava index, Journal of Computer and Mathematical Sciences, 8(6) (2017) 235-242.

17. V.R.Kulli, Some Gourava indices and inverse sum indeg index of certain networks, International Research Journal of Pure Algebra, 7(7) (2017) 787-798. 